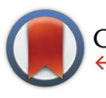

CrossMark

Cite this: Polym. Chem., 2017, 8 , 1061

\title{
Soft and rigid core latex nanoparticles prepared by RAFT-mediated surfactant-free emulsion polymerization for cellulose modification - a comparative study $\dagger$
}

\author{
J. Engström, ${ }^{\text {a,b }}$ F. L. Hatton, ${ }^{a}$ L. Wågberg, ${ }^{a, b}$ F. D'Agosto, ${ }^{c}$ M. Lansalot, ${ }^{c}$ \\ E. Malmström ${ }^{a}$ and A. Carlmark ${ }^{\star a, b}$
}

\begin{abstract}
Latex nanoparticles comprising cationically charged coronas and hydrophobic cores with different glass transition temperatures $\left(T_{\mathrm{g}}\right)$ have been prepared by surfactant-free, RAFT-mediated emulsion polymerization, where the particles form through a polymerization-induced self-assembly (PISA) type mechanism. Poly(2-dimethylaminoethyl methacrylate-co-methacrylic acid) (P(DMAEMA-co-MAA)) was utilized as a hydrophilic macroRAFT agent for the polymerization of methyl methacrylate (MMA) or $n$-butyl methacrylate (nBMA), respectively, resulting in two different latexes, with either a core of high (PMMA) or low (PnBMA) $T_{\mathrm{g}}$ polymer. By varying the molar mass of the hydrophobic block, latexes of different sizes were obtained ( $D_{H}$ ca. 40-120 nm). The adsorption of the latexes to cellulose model surfaces and cellulose nanofibrils (CNF) was studied using quartz crystal microbalance with dissipation monitoring (QCM-D). The surfaces with adsorbed PnBMA latexes yielded hydrophobic surfaces both before and after annealing, whereas surfaces with adsorbed PMMA latex became hydrophobic only after annealing, clearly showing the influence of the $T_{\mathrm{g}}$ of the core. The latexes were also used to modify macroscopic cellulose in the form of filter papers. Similar to the CNF surfaces, no annealing was required to achieve hydrophobic surfaces with PnBMA latexes. Finally, nanocomposites of CNF and the polymer nanoparticles were prepared through a one-pot mixing procedure. It was found that the largest synthesized PMMA latex (120 nm) facilitated a more strainable CNF network at 50\% relative humidity, with a nearly $200 \%$ increase in strain at break compared to the neat CNF reference film as well as to the composite films with PnBMA latexes or to the smaller sized PMMA latexes. This difference was attributed to the spherical shape and rigidity of the large PMMA latex nanoparticles during composite formation. This highly interesting result should indeed be considered in the future design of novel biocomposites.
\end{abstract}

Received 30th October 2016 Accepted 28th December 2016 DOI: $10.1039 / \mathrm{c} 6$ py01904h rsc.li/polymers

\section{Introduction}

To support the transformation to a sustainable society there is an urge to replace fossil-based materials with counterparts from renewable resources. Cellulose, from different sources such as wood, is one of the most promising natural polymers and has significant potential to be further exploited in

\footnotetext{
${ }^{a}$ Fibre and Polymer Technology, KTH Royal Institute of Technology,

10044 Stockholm, Sweden.E-mail: annac@kth.se

${ }^{b}$ Wallenberg Wood Science Centre, KTH Royal Institute of Technology,

10044 Stockholm, Sweden

${ }^{c}$ Université de Lyon, Univ Lyon 1, CPE Lyon, CNRS, UMR 5265, C2P2 (Chemistry,

Catalysis, Polymers \& Processes), Team LCPP Bat 308F, 43 Bd du 11 Novembre 1918, 69616 Villeurbanne, France

$\dagger$ Electronic supplementary information (ESI) available. See DOI: 10.1039/ c6py01904h
}

material science. Due to its high abundance, renewability, low cost and interesting mechanical properties, cellulose shows promise in applications such as barriers, coatings, free standing films and composites. ${ }^{1-5}$ Recently, much attention has been drawn to the nanosized components from the cellulose fibers, such as cellulose nanocrystals (CNC) and cellulose nanofibrils (CNF), owing to their unique material properties. CNF, having a high aspect ratio, and films from CNF having excellent oxygen barrier properties (under dry conditions), are foreseen to find applications in bio(nano)composites. However, the interaction between the inherently polar cellulose surface and non-polar matrices in fibre/fibril-reinforced composites needs to be carefully tailored in order to avoid aggregation and to achieve a high interfacial adhesion. ${ }^{6}$ The tailoring of the cellulose surfaces can be achieved by different modification routes such as covalent grafting of polymers, ${ }^{7-10}$ physical adsorption of polyelectrolytes and tailored block 
copolymers $^{11-13}$ or modification with small molecules. ${ }^{14}$ Physical adsorption of tailored block copolymers is an interesting approach, where the block copolymer is typically composed of an anchoring block (e.g. a cationic polyelectrolyte) and a functional block. ${ }^{15}$ The latter could be either hydrophobic, with the purpose of compatibilizing the cellulose with hydrophobic polymer matrices, or carry another function, such as thermoresponsivity. ${ }^{13}$ As adsorbing blocks, protonated tertiary amines are commonly utilized as they adsorb readily onto the negatively charged cellulose due to electrostatic interactions and entropy gain. ${ }^{12,16-19}$ One structure explored in several reports in the literature is poly(2-dimethylaminoethyl methacrylate) (PDMAEMA). DMAEMA can be polymerized by reversible deactivation radical polymerization (RDRP) techniques, such as atom transfer radical polymerization $(\mathrm{ATRP})^{13,16,17}$ and reversible addition-fragmentation chain transfer (RAFT) polymerization, ${ }^{20-23}$ resulting in PDMAEMA chains with controlled molar masses and low dispersity. Furthermore, PDMAEMA can be utilized as a macroinitiator or macromolecular RAFT agent (macroRAFT) for chain extension, due to the 'living' chain ends. ${ }^{23-26}$ In previous work, PDMAEMA macroRAFTs were successfully employed for the surfactant-free emulsion polymerization of styrene $e^{27}$ and methyl methacrylate (MMA), ${ }^{28}$ the latter resulting in amphiphilic block copolymers that self-assemble simultaneously into latex nanoparticles according to a process denoted polymerization-induced self-assembly (PISA). ${ }^{29-31}$ PISA was pioneered by Hawkett et al. ${ }^{32,33}$ using RAFT and this methodology have been expanded to various macroRAFT agents, enabling one-pot procedures for the nanoparticle preparation that can easily be surface-engineered by the proper choice of the starting macroRAFT. ${ }^{34,35}$

Latex nanoparticles are highly interesting for cellulose modification as the modification can be conducted in allaqueous conditions and the technique is already well-established in industry. Latex nanoparticles (poly(styrene-co-butadiene)) have been shown to, for example, enhance the tensile strength of paper sheets, as investigated by Alince et al. ${ }^{36,37}$ Additionally, composites composed of cellulose adsorbed with elastomeric core-shell latex particles of poly( $n$-butyl acrylateco-methyl methacrylate/2-ethylhexylacrylate-co-styrene) exhibited improved mechanical properties, increasing both impact and tensile strengths. ${ }^{38}$

Inspired by the above studies, we previously reported the synthesis of cationic latex nanoparticles by RAFT-mediated emulsion polymerization, utilizing a PDMAEMA-based macroRAFT, for the polymerization of MMA. The procedure resulted in latexes of a narrow size distribution, where the size could be controlled by the molar mass of the hydrophobic block. The nano-sized particles were subsequently adsorbed to cellulose model surfaces in a quartz crystal microbalance with dissipation monitoring (QCM-D), resulting in hydrophobic cellulose surfaces where the hydrophobicity could be further increased by annealing. ${ }^{28}$ The critical advantage with this approach is that it can be conducted in all water-borne systems, and that excellent control over the nanoparticles is achieved.
The aim of the present work was to further investigate the adsorption of nano-sized latexes onto cellulose substrates, studying the influence of the $T_{\mathrm{g}}$ of the particle core. The underlying principle is that the areal saturation of a substrate can be increased if the latexes are able to spread on the surface and hence coat the substrate to a greater extent. A low $T_{\mathrm{g}}$ core particle should be able to accomplish this more efficiently than one with a high $T_{\mathrm{g}}$ core. For this reason, two hydrophobic monomers were considered: MMA and $n$-butyl methacrylate (nBMA). As in our previous study, the latexes were produced by surfactant-free RAFT-mediated emulsion polymerization and the size of the particles was varied by varying the degree of polymerization (DP) of the hydrophobic block. The particles were adsorbed to CNF, cellulose model surfaces in QCM-D, as well as to filter papers. Furthermore, to expand the toolbox for composite formation, a set of composite films with $25 \mathrm{wt} \%$ latex and $75 \mathrm{wt} \% \mathrm{CNF}$ were produced and investigated to show the proof of principle for composite formation with the prepared latexes.

\section{Experimental section}

\section{Materials}

2-Dimethylaminoethyl methacrylate (DMAEMA, Aldrich, 98\%), methyl methacrylate (MMA, Acros, 99\%), $n$-butyl methacrylate (nBMA, Sigma Aldrich, 99\%) 2,2'-azobis(2-methylpropionamidine) dihydrochloride (AIBA, Aldrich, 97\%), hydrochloric acid ( $\mathrm{HCl}$, VWR Prolabo, $35 \mathrm{wt} \%$, technical grade), 1,3,5-trioxane (Aldrich, $\geq 99 \%$ ), sodium chloride (VWR), potassium chloride (Merck), sodium chlorite (puriss p.a.), sodium hypochlorite (14\% solution), 2,2,6,6-tetramethyl-1-piperidineyloxy (TEMPO), all purchased from Sigma Aldrich, and sodium bromide (Alfa Aesar, 99+\%) were used as received. Poly(ethylene imine) (PEI, $M_{\mathrm{n}}=60000 \mathrm{~g} \mathrm{~mol}^{-1}$ ) were purchased from Acros. Poly(vinyl amine) (PVAm, Lupamin 5095, $M_{\mathrm{w}}=45000$ $\mathrm{g} \mathrm{mol}^{-1}$ ) was kindly supplied by BASF, Germany. Water used was either deionized or MilliQ water. 4-Cyano-4-thiothiopropylsulfanyl pentanoic acid (CTPPA) was synthesized according to literature procedure. ${ }^{39-41}$ Munktell filter paper grade 3 was used for adsorption test (Ahlstrom, Munktell). The pulp used for the preparation of cellulose nanofibrils was a never-dried dissolving pulp (60\% Norwegian spruce and 40\% Scots Pine) kindly supplied by Domsjö Aditya Birla AB, Domsjö, Sweden. The preparation of cellulose nanofibrils was conducted using a TEMPO-oxidation at $\mathrm{pH} 6.8$ in phosphate buffer to ease the liberation of the fibrils from the fibres, according to a method from Saito et al. ${ }^{42,43}$ to reach a charge density of $\sim 600 \mu \mathrm{eq} \mathrm{g}{ }^{-1}$, as measured by conductometric titration. ${ }^{44}$ After TEMPO-oxidation the oxidized fibres were passed through a high-pressure homogenizer (Microfluidizer M-110EH, MicrofluidicsCorp) by two passes through $400 \mu \mathrm{m}$ and $200 \mu \mathrm{m}$ chambers at $1000 \mathrm{bar}$ and four passes through $200 \mu \mathrm{m}$ and $100 \mu \mathrm{m}$ at $1650 \mathrm{bar}$, to produce a gel at $0.89 \mathrm{wt} \%$ dry content, similarly to the method used by Cervin et $a l^{45}$ The QCM crystals used were AT-cut crystals (5 MHz resonance frequency) with an active surface of 
sputtered silica (50 nm thickness) supplied by Q-sense AB. The cellulose fibres (Domsjö Dissolving Plus; Domsjö Aditya Birla $\mathrm{AB}$, Domsjö, Sweden) used for the preparation of cellulose model surfaces were carboxymethylated to obtain anionic carboxylic charges $\left(350 \mu \mathrm{eq} \mathrm{g}^{-1}\right)$ on the cellulose fibres prior to use according to a procedure described by Wågberg et al. ${ }^{46}$

\section{Instrumentation and methods}

Nuclear magnetic resonance (NMR). The polymerization of DMAEMA was monitored by ${ }^{1} \mathrm{H}-\mathrm{NMR}$ with a Bruker Avance AM $400 \mathrm{NMR}$ instrument using $\mathrm{D}_{2} \mathrm{O}$ as solvent. For the estimation of conversion of the monomer and for the degree of hydrolysis, 1,3,5-trioxane was used as an internal reference. The final latex particles were analyzed with ${ }^{1} \mathrm{H}$-NMR to analyze the final structure after freeze-drying and dissolution in $\mathrm{CDCl}_{3}$.

Gravimetric analysis. The conversion of monomers during the emulsion polymerization was monitored gravimetrically; samples were withdrawn at different reaction times and dried in fume hood overnight, allowing the dry content to be calculated.

Size exclusion chromatography (SEC). The analysis of the number-average molar mass $\left(M_{\mathrm{n}}\right)$, weight-average molar mass $\left(M_{\mathrm{w}}\right)$ and dispersity $(\nexists)$ for all latex particles was performed with a TOSOH EcoSEC HLC-8320GPC system equipped with an EcoSEC RI Detector and three columns (PSS PFG $5 \mu \mathrm{m}$; Microguard, $100 \AA$, and $300 \AA$; MW resolving range: 100-300 $000 \mathrm{~g} \mathrm{~mol}^{-1}$ ) from PSS GmbH, using DMF with $0.01 \mathrm{M}$ $\mathrm{LiBr}$ as the mobile phase at $50{ }^{\circ} \mathrm{C}$ with a flow rate of 0.2 $\mathrm{mL} \min ^{-1}$. A conventional calibration method with PMMA standards ranging from 700 to $2000000 \mathrm{~g} \mathrm{~mol}^{-1}$ was used. All samples were freeze-dried prior to dilution in the mobile phase before injection. Corrections for flow rate fluctuations were made using toluene as an internal standard.

Differential scanning calorimetry (DSC). DSC analysis was performed with a Mettler Toledo DSC. All latex particles and the macroRAFT were analyzed with heating and cooling rate of $10{ }^{\circ} \mathrm{C}$ per minute in nitrogen atmosphere. The samples were freeze-dried prior to analysis. The method used was heating from -60 to $150{ }^{\circ} \mathrm{C}$, equilibrium for 5 minutes and then cooling from 150 to $-60{ }^{\circ} \mathrm{C}$, equilibrium for 5 minutes and a second heating from -60 to $150{ }^{\circ} \mathrm{C}$. Data from second heating were used to calculate the glass transition temperature for all samples.

Dynamic light scattering (DLS). The hydrodynamic radius $\left(D_{\mathrm{H}}\right)$, polydispersity index $(\mathrm{PdI})$ and electrophoretic mobility (zeta potential $(\zeta)$ ) of the latex particles were determined with a Malvern Zetasizer NanozS at $25{ }^{\circ} \mathrm{C}$. For the particle size measurements $\left(D_{\mathrm{H}}\right.$ and PdI) two concentrations were used ( $3 \mathrm{~g} \mathrm{~L}^{-1}$ and $0.1 \mathrm{~g} \mathrm{~L}^{-1}$ ) and the particles were diluted in either pure MilliQ water, $5 \mathrm{mM}$ sodium phosphate buffer or $1 \mathrm{mM} \mathrm{KCl}$. For the measurement of zeta potential, the concentration of latex was kept at $0.1 \mathrm{~g} \mathrm{~L}^{-1}$ diluted in $1 \mathrm{mM} \mathrm{KCl}$ in MilliQ water.

Fourier transform infrared spectroscopy (FTIR). Infrared spectra of latex saturated filter papers and composite films were recorded with a Perkin-Elmer Spectrum 2000 FT-IR equipped with a MKII Golden Gate, single reflection ATR System (from Specac Ltd, London, UK). The utilized ATR- crystal was a MKII heated Diamond $45^{\circ}$ ATR Top Plate. All samples were analyzed by 16 scans, two or more times to achieve a representative curve and normalized to the crystal region at 2400 to $1900 \mathrm{~cm}^{-1}$.

Polyelectrolyte titration (PET). The inherent charge density was measured for all latex particles and the hydrophilic macroRAFT with a PET using a 716 DMS Titrino (Metrohm, Switzerland) with potassium poly(vinyl sulfate) (KPVS) as the titrant and ortho-toluidine blue (OTB) as the indicator. The change in color was recorded with a Fotoelektrischer Messkopf 2000 (BASF) and the amount of KPVS needed to titrate to equilibrium was calculated according to a method described by Horn et al. ${ }^{47}$

Transmission electron microscopy (TEM). Thin liquid films of the latex suspension were deposited onto 300 mesh holey carbon films (AgarScientific, UK) and quenched in liquid ethane using a cryo-plunge workstation (LPS Orsay). The specimens were then mounted on a precooled Gatan 626 specimen holder, transferred into the Philips CM120 microscope operating at an accelerating voltage of $120 \mathrm{kV}$ (Centre Technologique des Microstructures (CT $\mu$ ), platform of the Claude Bernard Lyon 1 University, Villeurbanne, France).

The number of particles per unit volume of the aqueous phase $\left(N_{\mathrm{p}}\right)$ was calculated using the diameter obtained from DLS $\left(D_{\mathrm{H}}, \mathrm{nm}\right)$ according to the equation below:

$$
N_{\mathrm{p}}=\frac{6 \tau}{\rho \pi D_{\mathrm{H}}^{2}}
$$

with $\tau$ the solids content of the latex $\left(\tau=\left(m_{\text {macroRAfT }}+\right.\right.$ conversion $\left.\times m_{\text {monomer }}\right) / V_{\text {water }}$, with $m_{\text {macroRAFT }}$ and $m_{\text {monomer }}$ the initial weight of hydrophilic macroRAFT and MMA or $n$ BMA, respectively, $V_{\text {water }}$ the initial volume of water) and $\rho$ the density of PMMA $\left(1.20 \mathrm{~g} \mathrm{~cm}^{-3}\right.$ ) or PnBMA (1.055 $\left.\mathrm{g} \mathrm{cm}^{-3}\right)$.

Silica coated quartz crystals. The silica coated quartz crystals, used for in situ preparation with a CNF layer, were first rinsed with MilliQ water, ethanol and finally again with MilliQ water and thereafter dried with $\mathrm{N}_{2}$. The crystals were then placed in air plasma cleaner (Model PDC 002, Harrick Scientific Corporation, NY, USA) under reduced air pressure for $120 \mathrm{~s}$ at $30 \mathrm{~W}$. The same rinsing steps were performed for the silica coated QCM crystals prior to preparation of the cellulose model surfaces starting with dissolved cellulose.

Quartz crystal microbalance with dissipation (QCM-D). A QCM-E4 from Q-sense $\mathrm{AB}$ with a continuous flow rate of $0.15 \mathrm{~mL} \mathrm{~min}^{-1}$ was used. This instrument measures the change in resonance frequency of the crystal, corresponding to a change in mass attached to the surface. To convert a change in frequency to its corresponding change in adsorbed mass per area unit, the Sauerbrey model $^{48}$ can be used for firmly anchored adsorbed layers:

$$
m=C\left(\frac{\Delta f}{n}\right)
$$

where $C$ is a sensitivity constant, $-0.177\left(\left(\mathrm{mg} \mathrm{m}^{-2}\right) \times \mathrm{Hz}^{-1}\right), \Delta f$ the change in resonance frequency $(\mathrm{Hz})$, and $n$ the overtone 
number. The so calculated mass includes both the solid adsorbed amount and the immobilized solvent in the adsorbed layer.

The QCM-D also detects the energy dissipation in the adsorbed layer which is related to the viscoelastic properties. A thin, rigid attached film is expected to yield a low change in dissipation. A more water-rich and mobile film is expected to yield a larger change in dissipation. The dissipation factor, $D$, is defined as:

$$
D=\frac{E_{\text {dissipated }}}{2 \pi E_{\text {stored }}}
$$

where $E_{\text {dissipated }}$ is the energy dissipated during one oscillation period, and $E_{\text {stored }}$, the energy stored in the oscillating system. Earlier investigations have shown that Sauerbrey model is also valid for layers with higher dissipations and comparable to the results achieved with more advanced models. ${ }^{18}$

Atomic force microscopy (AFM). A Multimode 8 (Bruker, USA) was used with the ScanAsyst in Air mode, using a cantilever with $70 \mathrm{kHz}$ resonance frequency, spring constant 0.4 $\mathrm{N} \mathrm{m}^{-1}$, and tip radius $2 \mathrm{~nm}$ (ScanAsyst-Air, Bruker, USA). Samples for imaging were used after the QCM-D experiments and drying in room temperature or after an annealing step (160 ${ }^{\circ} \mathrm{C}$ for 1 hour).

Field emission scanning electron microscope (FE-SEM). Latex saturated filter papers were analyzed with FE-SEM performed on a Hitachi S-4800 to investigate the surfaces. The FE-SEM was run at $1.0 \mathrm{kV}$ and $3.0 \mathrm{kV}$ acceleration voltage if nothing else was stated and pictures were acquired at different magnifications, stated in each image. The samples were mounted on a metal stub with carbon tape and coated with a $5 \mathrm{~nm}$ layer of Pt/Pd with a Cressington 208HR sputter coater.

Contact angle measurements (CAM). Contact angle measurements were performed at $50 \%$ relative humidity $(\mathrm{RH})$ and $23{ }^{\circ} \mathrm{C}$ with a KSV instrument CAM 200 equipped with a Basler A602f camera, using $3 \mu \mathrm{L}$ droplets of MilliQ water. A YoungLaplace fitting mode, supplied by KSV was used to process the images. The contact angle values reported were those observed after $20 \mathrm{~s}$ of measurement when the drop had reached its equilibrium spreading on the substrates.

Ultra-turrax disintegration. CNF gels were dispersed in deionized water at target concentrations of $0.1 \mathrm{~g} \mathrm{~L}^{-1}$ or $0.2 \mathrm{wt} \%$ prior to use with a $\mathrm{T} 25$ digital ULTRA-TURRAX®. Disintegration was performed in a glass flask as container and the volume was depending on the amount needed. Level 9 and $10000 \mathrm{rpm}$ were used for 20 minutes.

Tensile testing. Composites films were stored in conditioned room at $23{ }^{\circ} \mathrm{C}$ and $50 \% \mathrm{RH}$ after drying in fume hood and the tensile testing was performed at the same conditions using an Instron 5944 with a $500 \mathrm{~N}$ load cell. The strain was measured by grip displacement. Strips, $5 \mathrm{~mm}$ in width and with a known thickness (85-111 $\mu \mathrm{m})$, were clamped with a free span of $15 \mathrm{~mm}$ and strained at a rate of $10 \% \mathrm{~min}^{-1}$. Analysis was performed on 4 or more specimens.

\section{Synthesis of PMMA and PnBMA latexes with RAFT-mediated surfactant-free emulsion polymerization}

PnBMA and PMMA latexes were obtained employing a preformed PDMAEMA-based macroRAFT synthesized in water according to a previously reported procedure. ${ }^{28}$ In a typical experiment (Table 1, sample $\mathrm{P} n \mathrm{BMA}_{1410}$ latex), the macroRAFT agent $(0.150 \mathrm{~g}, 36.3 \mu \mathrm{mol})$ was added to a $50 \mathrm{~mL}$ round bottom flask equipped with a magnetic stirring bar followed by addition of deionized water $(37.1 \mathrm{~mL})$ to reach a total final dry content of $16.7 \mathrm{wt} \%$. The monomer, $n \mathrm{BMA}(7.27 \mathrm{~g}$, $51.1 \mathrm{mmol}$, target DP 1410) was added. An aqueous solution of the initiator 2,2'-azobis(2-methylpropionamidine) dihydrochloride (AIBA) (3.4 $\left.\mathrm{g} \mathrm{L} \mathrm{L}^{-1}\right)$ was added to the reaction mixture $(1.19 \mathrm{mg}, 4.4 \mu \mathrm{mol}$ in $1: 8.25$ molar ratios to the macroRAFT). The flask was placed in a water/ice bath and the reaction mixture was degassed with argon for 30 minutes and thereafter immersed into an oil bath pre-heated to $70{ }^{\circ} \mathrm{C}$. All reactions were performed for 120 minutes. The conversion of monomer was monitored by gravimetric analysis of the dry content by withdrawing samples during the reaction. The same procedure was followed for the synthesis of the two other PnBMA latexes, and the three PMMA latexes (see Table 1 and ESI Table S2 $\dagger$ ). All formed latexes were analyzed by ${ }^{1} \mathrm{H}-\mathrm{NMR}$ and SEC.

\section{Adsorption to cellulose model surfaces}

PnBMA latexes were adsorbed onto cellulose model surfaces in the QCM-D, according to a previously described method for PMMA latexes. ${ }^{28}$ A stable baseline was first achieved with

Table 1 Data for the RAFT-mediated surfactant-free emulsion polymerizations and the resulting polymer properties

\begin{tabular}{|c|c|c|c|c|c|c|}
\hline Sample & Target $\mathrm{DP}^{a}$ & Monomer conversion (\%) & $M_{\mathrm{w}}{ }^{c}\left(\mathrm{~g} \mathrm{~mol}^{-1}\right)$ & $M_{\mathrm{n}}^{c}\left(\mathrm{~g} \mathrm{~mol}^{-1}\right)$ & $\bigoplus_{M}^{c}$ & $M_{\mathrm{n}, \text { theory }}{ }^{d}\left(\mathrm{~g} \mathrm{~mol}^{-1}\right)$ \\
\hline MacroRAFT P(DMAEMA-co-MAA) & 25 & $98^{b}$ & n.a & n.a & n.a & 3930 \\
\hline $\mathrm{PMMA}_{176}$ latex & 176 & 91 & 100900 & 42410 & 1.5 & 20176 \\
\hline $\mathrm{PMMA}_{705}$ latex & 705 & 97 & 304400 & 214700 & 1.4 & 72624 \\
\hline $\mathrm{PMMA}_{1410}$ latex & 1410 & 92 & 564900 & 340100 & 1.7 & 134051 \\
\hline $\mathrm{P} \mathrm{BMA}_{176}$ latex & 176 & 91 & 85990 & 48400 & 1.8 & 26911 \\
\hline $\mathrm{P}_{n} \mathrm{BMA}_{705}$ latex & 705 & 97 & 310500 & 223100 & 1.4 & 101379 \\
\hline${\mathrm{P} n \mathrm{BMA}_{1410} \text { latex }}$ & 1410 & 87 & 495600 & 350700 & 1.4 & 178573 \\
\hline
\end{tabular}

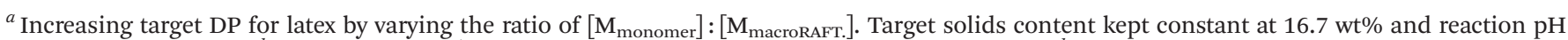

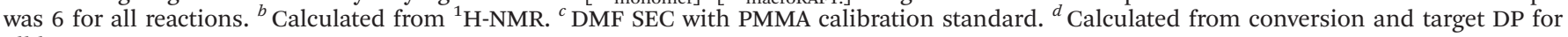
all latexes. 
MilliQ water before introducing the latexes dispersed in MilliQ water at concentration of $0.1 \mathrm{~g} \mathrm{~L}^{-1}$ with a flow rate of 0.15 $\mathrm{mL} \min ^{-1}$ until equilibrium was achieved, followed by a rinsing step with MilliQ water.

\section{Adsorption to CNF surfaces}

The adsorption of latexes (PMMA and PnBMA) onto CNF surfaces was monitored by QCM-D. The CNF surfaces were formed in situ by the initial introduction of an anchoring layer of poly(ethylene imine) (PEI) at a concentration of $0.1 \mathrm{~g} \mathrm{~L}^{-1}$ in $10 \mathrm{mM} \mathrm{NaCl}$ (pH adjusted to pH 10 with $10 \mathrm{mM} \mathrm{NaOH}$ ) until saturation, followed by a rinsing step with MilliQ water. In the next step, a layer of a CNF dispersion (disintegrated with an ultra-turrax at $9000 \mathrm{rpm}$ for $20 \mathrm{~min}$ ) was adsorbed at neutral $\mathrm{pH} \mathrm{7,} \mathrm{at} \mathrm{a} \mathrm{concentration} \mathrm{of} 0.1 \mathrm{~g} \mathrm{~L}^{-1}$, followed by a MilliQ water rinsing step, in accordance to previous measurements performed by Larsson et al. ${ }^{13}$ and Aulin et al. ${ }^{13,18}$ After rinsing with MilliQ water, the latexes were introduced at a concentration of $0.1 \mathrm{~g} \mathrm{~L}^{-1}$ in a $5 \mathrm{mM}$ sodium phosphate buffer $(\mathrm{pH}$ 6.8) to ensure a stable dispersion until a plateau was reached, followed by a rinsing step with MilliQ water. Reference crystals with PEI and CNF layer were investigated in the same buffer but without the adsorption of latexes. The crystals were analyzed by CAM and AFM.

\section{Adsorption to filter paper}

The latexes (PMMA or PnBMA) were adsorbed onto Munktell cellulose filter paper grade $3\left(2 \times 3 \mathrm{~cm}^{2}\right)$, using the following procedure: water dispersions of latex particles were diluted to a concentration of $3 \mathrm{~g} \mathrm{~L}^{-1}$ in MilliQ water in a $10 \mathrm{~mL}$ vial, after which a filter paper was immersed in the solution. The mixtures were left on a shaking table overnight to ensure complete adsorption (kinetics from QCM-D adsorption). The papers were thoroughly rinsed with MilliQ water and left in vials filled with MilliQ water overnight. The latex adsorbed papers were then rinsed again with MilliQ water and left in a conditioned room at $23{ }^{\circ} \mathrm{C}$ and $50 \% \mathrm{RH}$ for 24 hours prior to further characterizations with FTIR, CAM and FE-SEM.

\section{Preparation of composite films}

A dispersion of CNF (116 mL) at a concentration of $0.26 \mathrm{wt} \%$ in MilliQ water was disintegrated with an ultra-turrax at 10000 rpm for $20 \mathrm{~min}$ in a $500 \mathrm{~mL}$ flask. The CNF dispersion was degassed for $30 \mathrm{~min}$ under vacuum to remove air bubbles. A dispersion of either $\mathrm{PMMA}_{176}$ latex, $\mathrm{PMMA}_{1410}$ latex, $\mathrm{P} \mathrm{BMA}_{1410}$ latex or PnBMA 176 latex $\left(3 \mathrm{~g} \mathrm{~L}^{-1}\right.$ diluted in a $5 \mathrm{mM}$ sodium phosphate buffer solution) were added to the CNF dispersion, under magnetic stirring (33.6 mL latex buffer dispersion to give $99 \mathrm{mg}$ total dry weight of latex). The mixtures had a total dry mass of $396 \mathrm{mg}$ and a CNF content of $75 \mathrm{wt} \%$. The latex and CNF dispersions were left under slow magnetic stirring for one hour to ensure maximal adsorption to the surfaces. The CNF and latex dispersion were vacuum filtered through a glass filter funnel $(7.2 \mathrm{~cm}$ in diameter) using a $0.65 \mu \mathrm{m}$ PVDF membrane, DVPP Millipore, USA in analogy to previous films of $\mathrm{CNF}^{1,2}$ with a targeted thickness of around
$80 \mu \mathrm{m}$ and grammage of $100 \mathrm{~g} \mathrm{~m}^{-2}$. After filtration, the films were left to dry in a petri dish in the fume hood prior to being placed in a conditioned room at $23{ }^{\circ} \mathrm{C}$ and $50 \% \mathrm{RH}$ for 24 hours for further characterizations. Annealing of films was performed in an oven preheated to $150{ }^{\circ} \mathrm{C}$ for $4 \mathrm{~h}$.

A reference film was also prepared, with unmodified CNF. This film was prepared as described above with the exception that $0.24 \mathrm{wt} \%$ dispersion was disintegrated prior to addition of $32.98 \mathrm{~mL}$ of $5 \mathrm{mM}$ sodium phosphate buffer to reach a final concentration of $0.2 \mathrm{wt} \%$ for film formation.

\section{Results and discussion}

\section{Synthesis of PMMA and PnBMA latex particles}

The successful synthesis of latex consisting of amphiphilic block copolymers of P(DMAEMA- $c o$-MAA)- $b$-P $n$ BMA is hereby reported using RAFT-mediated surfactant-free emulsion polymerization. For comparison, previously reported P(DMAEMA-co-MAA)- $b$-PMMA ${ }^{28}$ was also synthesized and investigated herein. However, these particles have already been thoroughly characterized in the previous study, and will therefore only be briefly discussed (see ESI $\uparrow$ for full characterization of the new batch of PMMA latexes). As previously described, a macroRAFT of PDMAEMA with a targeted DP of 25 was synthesized by RAFT in water. However, the unavoidable hydrolysis of DMAEMA units led to the incorporation of less than $4 \%$ of methacrylic acid (MAA) units (ESI Table S1 and Fig. S1 $\dagger$ ). The resulting macroRAFT (P(DMAEMA-co-MAA)), positively charged at the working $\mathrm{pH}$ 6, was subsequently chain extended using surfactant-free emulsion polymerization of $n \mathrm{BMA}$, targeting different DPs of the hydrophobic block (see detailed experimental conditions in Table S2 $\dagger$ ). All experiments resulted in stable latexes, and the obtained conversions were above $87 \%$ (Table 1). The kinetics are in accordance with what is typically observed for PISA systems, with an inhibition period corresponding to the time required for the P(DMAEMA$c o$-MAA)- $b$-P $n$ BMA chains to be sufficiently surface active to self-assemble and nucleate particles (Fig. 1a). As shown in
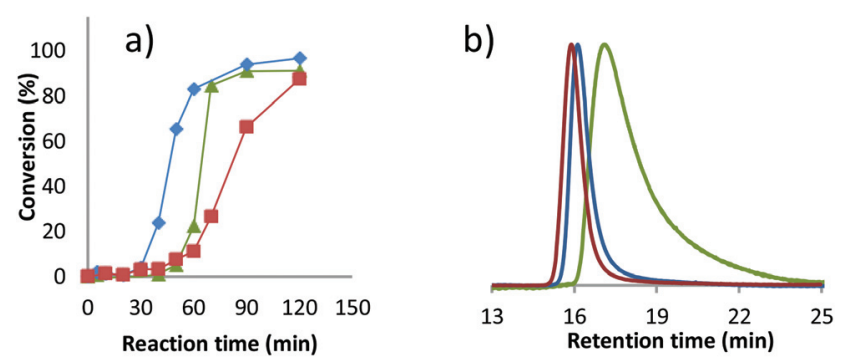

Fig. 1 Conversion curves from gravimetric analysis of emulsion polymerization of nBMA (a) and size exclusion chromatograms of PnBMA latexes (b): PnBMA176 latex (green triangles), PnBMA705 latex (blue diamonds) and PnBMA1410 latex (red squares). In (b) the different latex from left to right; PnBMA1410 latex (red line), PnBMA705 latex (blue line) and PnBMA176 latex (green line). 
Fig. 1b, monomodal molar mass distributions were observed for all PnBMA latexes, and increasing the targeted DP of the PnBMA hydrophobic segment ( $\mathrm{DP}=176,705$, or 1410) resulted in an increase of the molar masses, which were however higher than expected. Relatively low dispersity values $\left(1.4<\emptyset_{\mathrm{M}}\right.$ $<1.8$ ) were obtained for all batches, although higher than expected if an excellent control over the chain growth had been achieved by RDRP, i.e. an efficient PISA process. The charged nature of the P(DMAEMA-co-MAA) segment and thus its poor solubility in the eluent may somehow hamper the reliability of the SEC analyses in terms of distribution and molar masses. Besides, as mentioned in our previous study, ${ }^{28}$ the charged nature of the chains may also impede the first addition-fragmentation steps and thus disturb the self-assembly process, explaining why the molar masses were higher than targeted.

PnBMA latexes were analyzed by cryo-transmission electron microscopy (cryo-TEM) (Fig. 2) to assess their particle shape and size. From the images it can be concluded that PnBMA particles were spherical, and that the dispersity of the particles was relatively low despite some smaller particles observed in all samples. The cryo-TEM also revealed that, as for the case of the PMMA particles previously reported, the size of the particles increased with increasing DP of the hydrophobic block.

Results from PMMA latex synthesis correlate well with previously published data from Carlsson et al. and with those from the PnBMA latexes. Indeed, conversions were above 91\%, molar masses of the PMMA chains were higher than expected but increased with the targeted DP, and the dispersity remained below 1.7 (Table 1 ).

All the latexes were further analyzed by DLS (Tables 2 and $\mathrm{S} 3 \dagger)$. For both types of latexes the PdI values indicate narrow

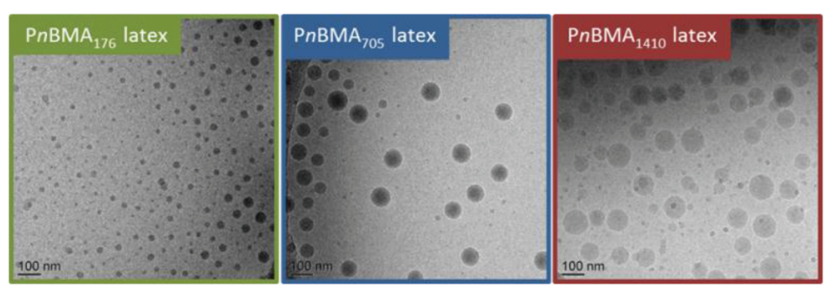

Fig. 2 Cryo-TEM images of PnBMA latexes. Scale bar is $100 \mathrm{~nm}$. size distributions (PdI values below 0.1), and the size increased with the molar mass of the hydrophobic block. When comparing PMMA and PnBMA for the same targeted DP, the sizes of the latex nanoparticles are similar, except for the $\mathrm{PMMA}_{1410}$ latex where the particles are slightly larger than for the Pn $\mathrm{BMA}_{1410}$ sample.

The number of particles per volume of water (Table 2) was calculated from eqn (1) using the particle size from DLS. According to these results there are slight differences between PnBMA and PMMA latexes. The water solubility of $n \mathrm{BMA}$ is almost 10 times lower than that of MMA $\left(0.2 \mathrm{~g} \mathrm{~L}^{-1}, 49\right.$ compared with $15.3 \mathrm{~g} \mathrm{~L}^{-1},{ }^{50}$ at $20{ }^{\circ} \mathrm{C}$ ) and as a result, there are initially fewer monomer molecules present in the water phase during the $n$ BMA polymerization compared to that of MMA. The time required reaching surface activity and particle nucleation is thus longer in the case of $n$ BMA. For $n$ BMA it took more than $30 \mathrm{~min}$ to reach above ca. 9\% conversion for all reactions compared to less than 20 min for MMA under the same conditions, and this could also affect the number of particles, as discussed previously by Chaduc et $a l^{51,52}$

The thermal properties of the latexes were investigated by DSC (Table 2). The detected glass transition temperatures show values between $32-36{ }^{\circ} \mathrm{C}$ for PnBMA latexes and 128-129 ${ }^{\circ} \mathrm{C}$ for PMMA latexes. This correlates well with literature values for homopolymers of PnBMA reported to be 20 to $32{ }^{\circ} \mathrm{C}^{53-55}$ and 105 to $120^{\circ} \mathrm{C}$ for PMMA. ${ }^{56}$

\section{Adsorption of latexes in QCM-D}

The adsorption of the P(DMAEMA-co-MAA)-stabilized PMMA latexes on cellulose model surface in the QCM-D has been reported earlier. ${ }^{28} \mathrm{~A}$ similar study was performed in the present work where PnBMA latexes were adsorbed in situ in the QCM-D onto two different types of surfaces in order to establish similarities or to identify dissimilarities between the high and low $T_{\mathrm{g}}$ core nanoparticles. In the first case, the PnBMA latexes were adsorbed to cellulose model surfaces (ESI Fig. $\mathrm{S} 2 \dagger)$ and in the second case, adsorption studies were performed for both the PMMA and PnBMA latexes onto an in situ formed layer of CNF.

\section{Adsorption onto cellulose model surfaces}

The adsorption of PnBMA latexes onto cellulose model surfaces in the QCM-D exhibited similar trends to those pre-

Table 2 Summarized data from analysis of PMMA and PnBMA latexes

\begin{tabular}{|c|c|c|c|c|c|c|}
\hline Sample & $D_{\mathrm{H}}^{a}(\mathrm{~nm})$ & $\mathrm{PdI}^{a}$ & Zeta potential $^{b}(\mathrm{mV})$ & Charge density $\left(\text { meq } \mathrm{g}^{-1}\right)^{c}$ & $T_{\mathrm{g}}{ }^{d}$ & $N_{\mathrm{P}}\left(10^{14} \mathrm{~mL}^{-1} \text { Latex }\right)^{e}$ \\
\hline $\mathrm{PMMA}_{176}$ latex & 36 & 0.07 & 41 & $1.000 \pm 0.149$ & 128 & 37.0 \\
\hline $\mathrm{PMMA}_{705}$ latex & 74 & 0.02 & 40 & $0.201 \pm 0.013$ & 128 & 4.30 \\
\hline $\mathrm{PMMA}_{1410}$ latex & 120 & 0.03 & 40 & $0.114 \pm 0.009$ & 129 & 1.19 \\
\hline $\mathrm{P} \mathrm{BMA}_{176}$ latex & 42 & 0.09 & 43 & $0.430 \pm 0.010$ & 36 & 25.7 \\
\hline $\mathrm{P}_{n} \mathrm{BMA}_{705}$ latex & 79 & 0.05 & 38 & $0.138 \pm 0.004$ & 35 & 6.03 \\
\hline${\mathrm{P} n \mathrm{BMA}_{1410} \text { latex }}$ & 96 & 0.05 & 40 & $0.087 \pm 0.001$ & 32 & 2.47 \\
\hline
\end{tabular}

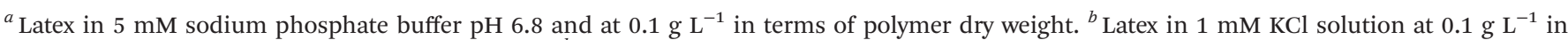

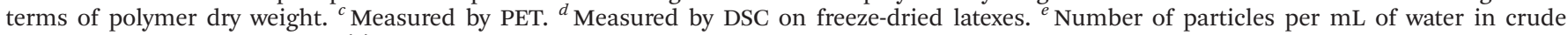
latexes are calculated from eqn (1) and taking into account the $D_{\mathrm{H}}$ from DLS measurements. 
viously observed for the PMMA latexes (calculated adsorbed mass from 4.3 to $39.1 \mathrm{mg} \mathrm{m}^{-2}$ with increasing particle size (50 to $146 \mathrm{~nm}, D_{\mathrm{H}}$ from DLS)). ${ }^{28}$ Indeed, for the same initial concentration of polymer particles $\left(0.1 \mathrm{~g} \mathrm{~L}^{-1}\right)$, the total adsorbed mass increased from 10.5 to $44.4 \mathrm{mg} \mathrm{m}^{-2}$ with increased particle size from 42 to $96 \mathrm{~nm}$ (Table 3 and ESI Fig. S2†). Similar to the values for PMMA latex previously reported for cellulose model surfaces, the maximum adsorbed amount can be governed by several factors. Firstly, the amount of available charges on the cellulose surface will determine the amount of latex that can be adsorbed before the surface charge has been compensated. From the adsorbed amount, when comparing the smallest and largest sized latexes $\left(\mathrm{P} n \mathrm{BMA}_{176}\right.$ latex and $\mathrm{P} \mathrm{BMA}_{1410}$ latex) with an almost 5 times difference in charge density, the total amount of adsorbed charges can be calculated to be $2.3 \times 10^{-6}$ and $1.9 \times 10^{-6}$ eq $\mathrm{m}^{-2}$, respectively (ESI eqn (S2) †), assuming spherical close-packing of the particles. The available surface area can be another limiting factor. In this case the total area covered by particles per QCM crystal can be calculated from the adsorbed amounts and found to be 0.19 and

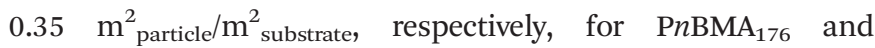
$\mathrm{P} n \mathrm{BMA}_{1410}$ latex (calculations described in ESI eqn (S3)†). Furthermore, the Debye-length in solution must be correlated to the size of the particles since particles which are too large will not adsorb in a 1:1 relationship with the charge on the surface. Hence, the size of the largest particle $\left(\mathrm{P} n \mathrm{BMA}_{1410}\right.$ latex, $96 \mathrm{~nm}$ ) is on the borderline for successful charge compensation, when considering that the electric double layer for $\mathrm{NaCl}$ is around $20 \mathrm{~nm}$ thick and therefore relatively long ranged due to the low concentrations (MilliQ water). ${ }^{57}$ Furthermore, the $T_{\mathrm{g}}$ of the particles may play a role since the latex with the lower $T_{\mathrm{g}}$ could possibly deform upon adsorption, while the latex with the higher $T_{\mathrm{g}}$ will not. In conclusion, there are several important parameters controlling the adsorbed amount of latex. In this case, considering the adsorbed amount of charges and the covered surface area, it is suggested that the adsorption coverage is mainly controlled by available charges.

\section{Adsorption onto CNF surface formed in situ}

An alternative way of investigating the adsorption to cellulose in the QCM-D is to adsorb a layer of CNF formed in situ in the
QCM-D rather than producing a cellulose model surface from regenerated cellulose. In this case, both the PMMA and P $n$ BMA latexes synthesized for this study were investigated. The latexes $\left(0.1 \mathrm{~g} \mathrm{~L}^{-1}\right)$ were introduced into the QCM-D and adsorbed onto the in situ formed CNF layer (Table 3). As for the cellulose model surfaces, the calculated adsorbed mass according to the Sauerbrey model increased with increasing DP for the PMMA latexes. However, for P $n$ BMA the trend was different as $\mathrm{P} n \mathrm{BMA}_{705}$ and $\mathrm{P} n \mathrm{BMA}_{1410}$ latexes show a negligible difference in mass. The smallest $\mathrm{P} n \mathrm{BMA}_{176}$ latex resulted in a higher adsorbed mass compared with its PMMA counterpart $\left(\mathrm{PMMA}_{176}\right.$ latex). The discrepancy may be an effect of the potential formation of clusters of particles on the surface in the wet phase due to the softer core of the PnBMA latex (Table 2) at the adsorption temperature $\left(25^{\circ} \mathrm{C}\right)$. The influence of charges on the adsorption is shown by the large mass adsorbed for $\mathrm{P} \mathrm{BMA}_{176}$ latex compared with $\mathrm{PMMA}_{176}$ latex (i.e. $46.8 \mathrm{mg} \mathrm{m}^{-2}$ and $20.1 \mathrm{mg} \mathrm{m}^{-2}$, respectively) since the charge density of $\mathrm{P} \mathrm{BMA}_{176}$ latex is only half that of the PMMA $_{176}$ latex. For the other two sizes and targeted DPs (705 and 1410) the adsorbed mass was similar for PnBMA and PMMA latexes which may be due to saturation of the surface. The influence of the charge on the adsorption is also supported by the detected difference between the model cellulose surfaces and the in situ formed layers since the model cellulose surfaces are made from fibres with a considerably lower

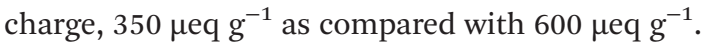

Fig. 3 clearly shows that the smaller the particle size, the faster the adsorption, as expected due to faster diffusion, and a clear indication that the adsorption is controlled by diffusion of the particles to the solid-liquid interface. Furthermore, the dissipation values for the PMMA latexes increase with the particle size. For the P $n$ BMA latexes the situation is not as clear and despite a large difference in size, the dissipation values are similar. This indicates that the lower $T_{\mathrm{g}}$ of P $n$ BMA has a significant influence on the viscoelasticity of the adsorbed surface layer. Furthermore, it can be hypothesized that the difference in $T_{\mathrm{g}}$ between the PMMA and $\mathrm{P} n \mathrm{BMA}$ cores could affect the wet cluster formation between latex particles, if one considers a shape destructive adsorption mechanism.

Table 3 Adsorption of latexes analyzed in QCM-D on cellulose model surfaces and in situ formed CNF layer

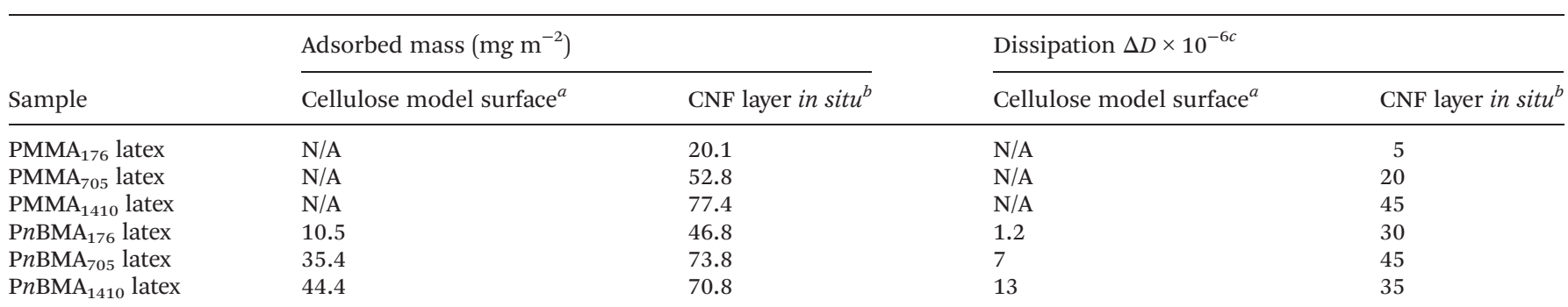

${ }^{a}$ Latexes analyzed in QCM-D on cellulose model surfaces, mass estimated from Sauerbrey model and eqn (2). ${ }^{b}$ Latexes analyzed in QCM-D on in situ CNF layer, mass estimated from Sauerbrey model and eqn (2). ${ }^{c}$ The dissipated energy and viscoelastic properties of the adsorbed layer estimated from eqn (3). 

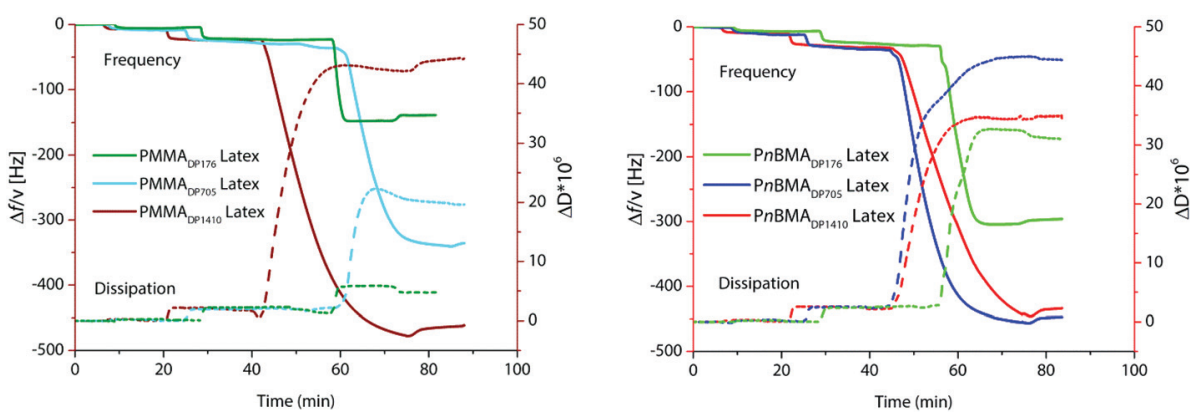

Fig. 3 QCM-D measurements of the adsorption of PMMA and PnBMA latexes onto a CNF layer formed in situ in the QCM-D. Left $y$-axis shows change in frequency for the third overtone and the right $y$-axis the dissipation, both over time.

Further information regarding the adsorption and the particles was obtained by analyzing the dried surfaces by AFM. As can be seen from Fig. 4 and 5, full surface coverage was not achieved for the largest particles, $\mathrm{P}_{\mathrm{BMA}} \mathrm{A}_{1410}$ latex and $\mathrm{PMMA}_{1410}$ latex, corroborating the QCM-D results. It has previously been noticed, in our work on cellulose model sur-

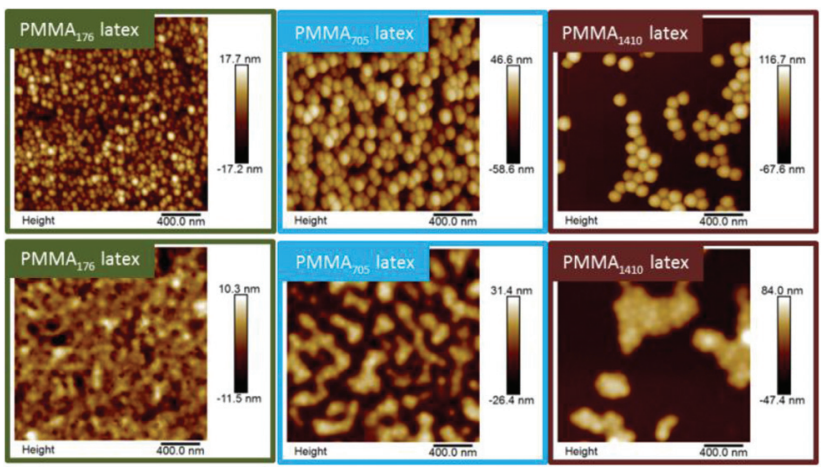

Fig. 4 AFM images of PMMA latexes adsorbed onto CNF surfaces. Top images are surfaces prior to annealing and the bottom images are the same surfaces after annealing for $1 \mathrm{~h}$ at $160^{\circ} \mathrm{C}$.

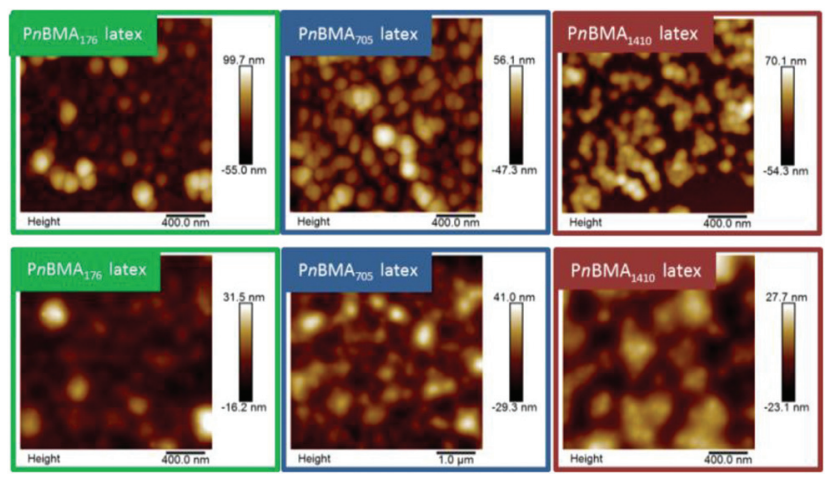

Fig. 5 AFM images of PnBMA latexes adsorbed onto CNF surfaces. Top images are surfaces prior to annealing and the bottom images are the same surfaces after annealing for $1 \mathrm{~h}$ at $160^{\circ} \mathrm{C}$. Scale on middle picture of $\mathrm{PnBMA}_{705}$ latex after annealing is higher due to difficulties in imaging the surface at higher resolution. faces, ${ }^{28}$ that the large PMMA1410 particles adsorbed with less close-packing compared to the smaller particles. Herein, these larger particles exhibit even lower affinity for the surface, which its believe to stem from the roughness of the CNF in situ formed surface in combination with the large particle size and low charge density. In the case of larger particles, only a small part of the surface of the entire particle will be able to interact with the charges on the CNF surface, and as the charge density of the particle is lower, the interaction between the particle and the surface is not as strong as in the case of smaller particles with higher charge density. However, in the case of all other latexes, the surface appears completely covered. Furthermore, all PMMA latex particles maintain their spherical shape upon adsorption (Fig. 4) compared to the surfaces adsorbed with PnBMA latexes that are significantly less uniform (Fig. 5). For PnBMA, there is a discrepancy between the measured heights from AFM compared to the measured diameters from DLS and TEM. This is likely an effect of the softer particles, which would be able to reshape and form clusters already at $25{ }^{\circ} \mathrm{C}$ which may also explain the larger mass adsorbed in QCM-D for all PnBMA latexes. For the PMMA latexes, the height values from AFM are close to the measured DLS values and there seems to be only minor, if any, coalescence of the particles for the non-annealed surfaces.

All the latex modified surfaces were annealed at $160{ }^{\circ} \mathrm{C}$ for $1 \mathrm{~h}$, well above the $T_{\mathrm{g}}$ of both PMMA and PnBMA particles. As previously reported $^{28}$ annealing caused the rigid PMMA particles to coalesce across the surface, exposing the hydrophobic core, which was also the case here, as is clearly shown in Fig. 4. For the PnBMA latexes the particles form clusters already prior to the annealing step and the images before and after annealing are therefore similar (Fig. 5).

As previously mentioned, the latexes are produced and adsorbed to cellulose in order to change the hydrophobicity of the surface and to improve the interfacial adhesion to hydrophobic matrices. The results from contact angle (CA) measurements and AFM roughness values of the latex treated surfaces are shown in Table 4 . The reference QCM crystal with PEI and CNF layer shows a contact angle of around $50^{\circ}$ both before and after annealing (contact angle and surface in AFM in ESI, Fig. S3-S6†). All surfaces show a high CA value prior to anneal- 
Table 4 Contact angle measurements and roughness values of latex adsorbed CNF surfaces and reference CNF surface

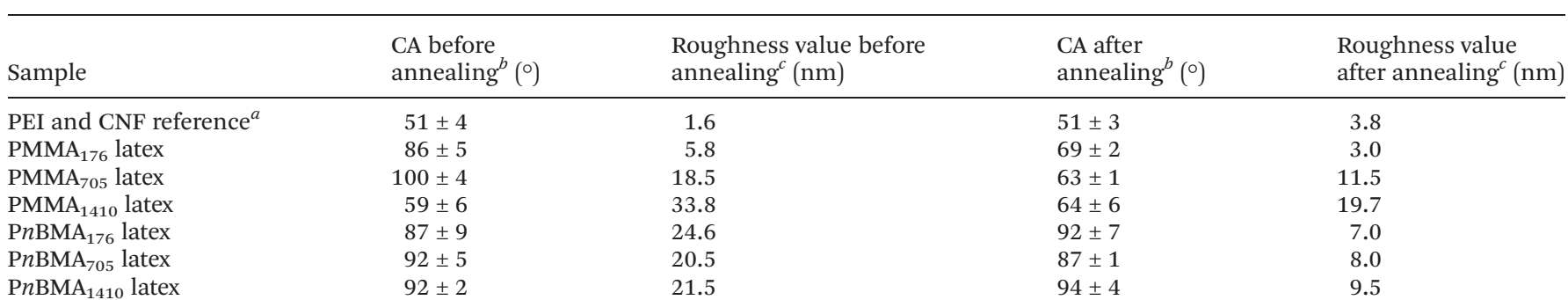

${ }^{a}$ Reference crystal with one adsorbed layer of PEI and one of CNF. ${ }^{b}$ Performed on at least three points on each surface. ${ }^{c}$ A total of five points on each surface.

ing and a decrease in CA after the annealing step. This was an expected result in the case of PnBMA latex adsorbed surfaces, but for the surfaces adsorbed with PMMA latexes this was a surprising result as the PMMA latexes should expose their hydrophilic corona prior to annealing. Indeed, in our previous study $^{28}$ annealing was required in order to obtain such a hydrophobic surface on the cellulose model surfaces. There could be numerous reasons for these results, as it is hard to distinguish between a change in surface energy and a significant change in surface roughness, both affecting the resulting contact angles. However, annealing of the surfaces resulted in a distinct decrease in surface roughness for the PMMA latex covered surfaces, which causes a decrease in contact angle. All surfaces coated with PnBMA latexes exhibit similar roughness values both before (21-25 nm) and after annealing (7-9.5 nm), a further testament of the spreading of these softer latexes on the surface upon adsorption. It is, however, very interesting to note that after annealing all the PMMA and PnBMA surfaces show similar contact angles, within their respective series, indicating that the treated surfaces have adopted the properties of the synthesized polymer as reported CA for PMMA film is around $68^{\circ}-74^{\circ}$ (ref. 58 and 59) and for PnBMA film around $88^{\circ} .{ }^{59}$

\section{Adsorption of PnBMA and PMMA latexes on cellulose filter paper}

The PnBMA and PMMA latexes were adsorbed to cellulose filter paper in order to further investigate the adsorption and coating properties of these materials. The interesting aspect of the filter paper is the fact that it has a significantly lower anionic charge density, and hence, the mechanism for adsorption may be different from the more highly charged cellulose model surface and CNF. The latex particles were adsorbed onto filter paper by immersing the papers in water suspensions containing the latexes. After adsorption, the papers were thoroughly rinsed with MilliQ water. FTIR was used to characterize the resulting composites and it was found that the latex particles had indeed adsorbed to the cellulose filter papers (Fig. 6 and 7). All samples exhibited a distinct peak in the carbonyl region, $1730 \mathrm{~cm}^{-1}$, 60,61 originating from the ester group in the side chain of P(DMAEMA-co-MAA), PMMA and PnBMA, respectively. This carbonyl peak is increasing with increasing molar mass of the hydrophobic blocks, which is in agreement

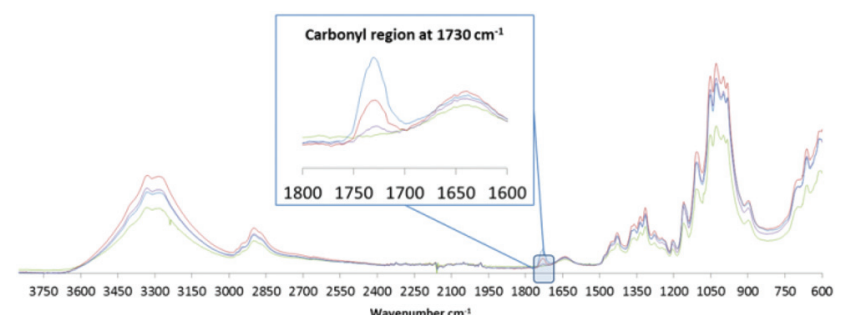

Fig. 6 FTIR spectra of PMMA-based latexes adsorbed onto filter paper: $\mathrm{PMMA}_{176}$ latex (purple line), $\mathrm{PMMA}_{705}$ latex (red line), $\mathrm{PMMA}_{1410}$ latex (blue line) and a reference filter paper (green line).

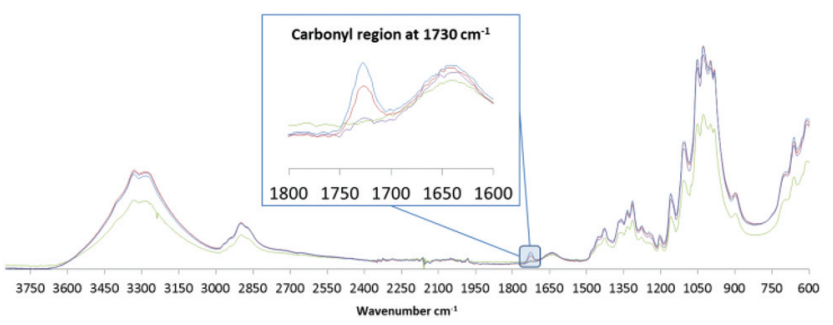

Fig. 7 FTIR spectra of PnBMA-based latexes adsorbed onto filter paper: $\mathrm{PnBMA}_{176}$ latex (purple line), $\mathrm{PnBMA}_{705}$ latex (red line), $\mathrm{PnBMA}_{1410}$ latex (blue line) and a reference filter paper (green line).

with the QCM-D results; increasing amount of polymer is adsorbed with increasing particle size of the latexes. Furthermore, the adsorbed mass of latexes appears to be relatively independent of the core, corroborating QCM-D analysis of the cellulose model surfaces. This also shows that the model experiments can be used to clarify the adsorption details for the adsorption of latex to macroscopic fibres, which was one of the objectives with the model experiments.

The filter papers were also analyzed by scanning electron microscopy (SEM) (Fig. 8). A remarkable difference between the PMMA latex adsorbed filter papers and the PnBMA latex adsorbed ones can be observed. The PMMA particles do not coalesce or form clusters on the fibre surface and retain their spherical shape upon adsorption and drying as expected due to the high $T_{\mathrm{g}}$. In the case of the PnBMA latexes, it is apparent that the spherical structure of the particles has disappeared, 


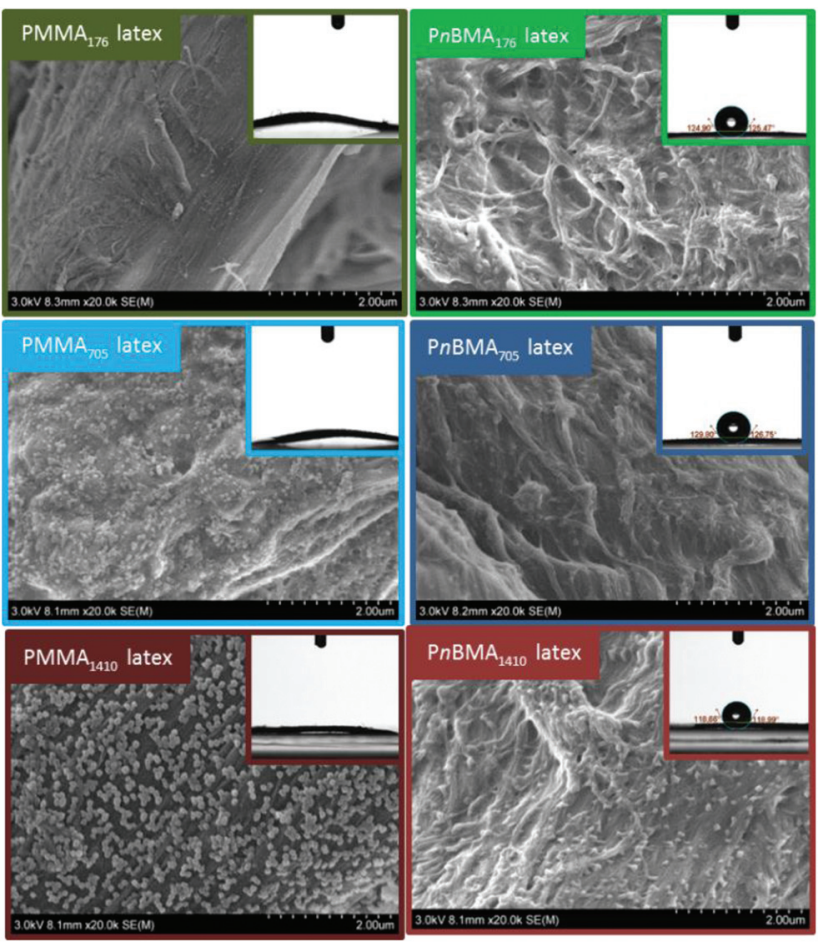

Fig. 8 SEM images and contact angle measurements of filter paper adsorbed with PMMA (left) and PnBMA (right) latexes prior to annealing.

due to adsorption and subsequent drying, and the surfaces appear to be covered with polymer, although some nanoparticles remained for PnBMA $_{1410}$ latex.

The CA of the resulting latex covered papers were also measured (Fig. 8). The PMMA latex adsorbed surfaces exhibit a hydrophilic character prior to annealing (ESI Table S4 $\dagger$ ), most probably due to the rigidity of the PMMA latex particles, having the hydrophilic corona of charged P(DMAEMA-co-MAA) exposed. The low measured contact angles could also be a consequence of poor surface coverage in this case. In the case of PnBMA latex adsorbed filter papers, the excellent coverage of these surfaces is also reflected in the high contact angles measured prior to annealing. This is another indication of the cluster forming and potentially coalescing nature of the low $T_{\mathrm{g}}$ core PnBMA latexes.

As for the cellulose model surfaces, the latex modified filter papers were subjected to annealing at $160{ }^{\circ} \mathrm{C}$ for $1 \mathrm{~h}$, and characterized by SEM and CA measurements (Fig. 9) as well as FTIR (Fig. S7 and S8 $\dagger$ ). Individual particles are no longer visible and the latex particles have spread across the surfaces in all the samples. The PMMA adsorbed surfaces turned hydrophobic after annealing, with contact angles above $100^{\circ}$ (ESI Table $\mathrm{S} 4 \dagger$ ). For the PnBMA adsorbed filter papers the annealing did not affect the results from CA measurements to a large extent, further corroborating previous results that the corresponding nanoparticles already coalesced before annealing. By FTIR it was shown that the quantity of latex were maintained on the filter papers, as expected, even after annealing, spectra

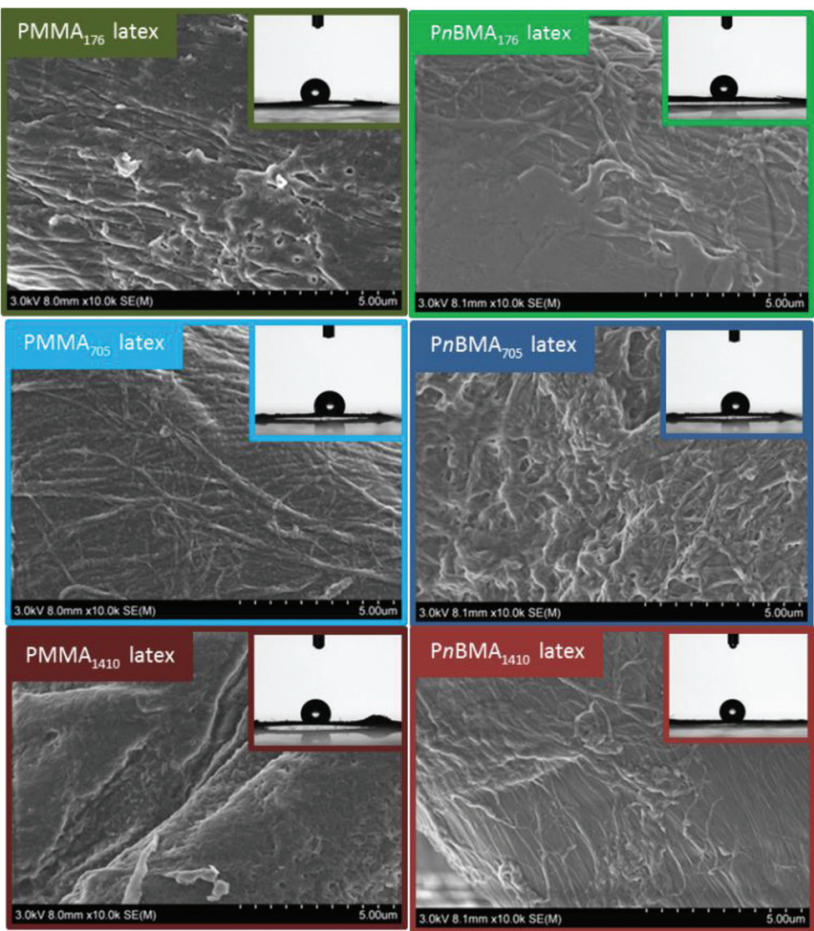

Fig. 9 SEM images and contact angle measurements of filter paper adsorbed with PMMA (left) and PnBMA (right) latexes after annealing at $160{ }^{\circ} \mathrm{C}$ for 1 hour.

shows similar results as compared to before annealing for the different adsorbed latexes (Fig. S7 and S8†).

\section{Composite films of CNF and PMMA or PnBMA latexes in} one-pot mixing and film formation

In order to investigate the possibility of forming one-pot fibril reinforced composites with a high cellulose content, latexes of PMMA or PnBMA (25 wt \% dry content in the final film) were mixed with CNF (75 wt\% dry content in the final film) water dispersions. $\mathrm{CNF} /$ polymer composites were formed by vacuum filtration at room temperature followed by drying at ambient temperature. The latexes investigated were $\mathrm{PMMA}_{176}$, $\mathrm{PMMA}_{1410}, \mathrm{P} n \mathrm{BMA}_{176}, \mathrm{P} n \mathrm{BMA}_{1410}$ as well as a reference sample containing only CNF.

The four composites and reference sample were evaluated by tensile testing (Table 5 ). The elastic modulus ( $E$-modulus)

Table 5 Tensile testing of CNF and latex nanoparticle composites

\begin{tabular}{llll}
\hline Sample & $\begin{array}{l}E \text {-Modulus } \\
(\mathrm{MPa})\end{array}$ & $\begin{array}{l}\text { Tensile } \\
\text { strength }(\mathrm{MPa})\end{array}$ & $\begin{array}{l}\text { Strain-at- } \\
\text { break (\%) }\end{array}$ \\
\hline CNF reference & $5950 \pm 590$ & $173 \pm 32$ & $13.6 \pm 4.0$ \\
CNF PMMA $_{176}$ latex & $4550 \pm 430$ & $120 \pm 9.1$ & $14.8 \pm 3.1$ \\
CNF PMMA $_{1410}$ latex & $3520 \pm 310$ & $117 \pm 3.0$ & $28.2 \pm 1.5$ \\
CNF PnBMA $_{176}$ latex & $4230 \pm 190$ & $116 \pm 14$ & $12.9 \pm 3.3$ \\
CNF PnBMA $_{1410}$ latex & $3870 \pm 270$ & $114 \pm 19$ & $16.1 \pm 5.4$ \\
CNF PMMA $_{1410}$ latex & $3540 \pm 385$ & $101 \pm 7.8$ & $16.7 \pm 3.2$
\end{tabular}


of PMMA has been reported to be between $0.6 \mathrm{GPa}$ (ref. 62) and 2.34 GPa (ref. 63) depending on the processing step, and for PnBMA values of around 1.2 GPa have been reported for thin films analyzed by nanointendation. ${ }^{64}$ Due to the higher stiffness of the CNF film compared with pure PMMA and PnBMA, the latexes were not expected to contribute to the stiffness of the composite materials, as was demonstrated by a decreased $E$-modulus for all samples compared to the CNF reference in this study. The results show that the small particle size of both $\mathrm{PMMA}_{176}$ latex and $\mathrm{P}_{n} \mathrm{BMA}_{176}$ latex gave a lower decrease of the composite $E$-modulus as compared to the large size of $\mathrm{PMMA}_{1410}$ latex and $\mathrm{P} n \mathrm{BMA}_{1410}$ latex. Furthermore, the tensile strength decreases for all samples, possibly due to the high load of particles that will not stiffen the CNF network but rather weaken it by disturbing contact points between CNF. The strength values are highly dependent on porosity, therefore it is difficult to draw any clear correlations from the investigated samples, as they possibly vary slightly in porosity. The strength of all composite films remains above $100 \mathrm{MPa}$. However, the composites containing latexes of largest size have significantly higher strain-at-break compared to the neat CNF film, especially the sample containing PMMA latexes where the difference is close to $200 \%$. In this case the particles remain intact after adsorption and it is suggested that they therefore can create contact points, so-called bridges, most likely between the positively charged corona and the negatively charged $\mathrm{CNF}$ in the dried state, which gives rise to a more strainable material. However, this bridging effect is not as apparent in the case of the softer PnBMA particles, as noted by the smaller increase of strain-at-break in the composite containing PnBMA ${ }_{1410}$ latex (Table 5). From FTIR measurements of the composite films (ESI Fig. S9†), it could be concluded that the two composites with $\mathrm{P} n \mathrm{BMA}_{1410}$ latex and $\mathrm{PMMA}_{1410}$ latex contained similar amount of latex particles, hence, the difference in strain-at-break stems from the rigidity of the PMMA particles after adsorption compared to the coalesced PnBMA particles. In order to test the hypothesis that it is the rigidity of the PMMA particles that has a positive effect on the strain-at-break, annealing was performed on the composite containing $\mathrm{PMMA}_{1410}$ latex $\left(150{ }^{\circ} \mathrm{C}\right.$ for $\left.4 \mathrm{~h}\right)$. The annealing resulted in a more brittle material with lower strain at break, $16 \%$ after annealing compared to $28 \%$ before (Table 5). From this highly interesting result it can be concluded that, indeed, the particle structure has a large effect on the strain-at-break.

The fracture surfaces of the composite films were investigated by SEM (Fig. 10). No significant difference in structure can be detected between $\mathrm{PMMA}_{176}, \mathrm{P}_{n} \mathrm{BMA}_{176}$, and $\mathrm{P} n \mathrm{BMA}_{1410}$ latex compared with the $\mathrm{CNF}$ reference film, but for the $\mathrm{PMMA}_{1410}$ latex the morphology is visibly different. Large particles are clearly seen, well distributed inside the cross-section, and rigid particles are visible throughout the entire surface.

The fracture surfaces of the annealed composite film with $\mathrm{PMMA}_{1410}$ latex were also studied by SEM to further investigate the potential role of rigid PMMA latex incorporation (Fig. 11). Compared with the composite before annealing, there is a large difference in terms of the layered structure, and it
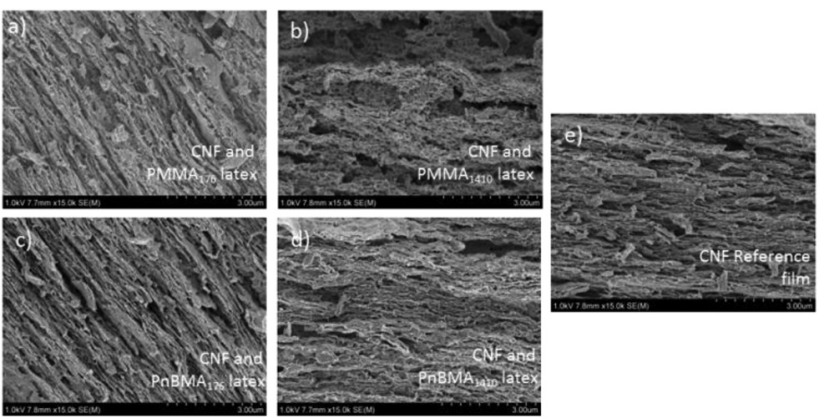

Fig. 10 SEM pictures of fracture surfaces after tensile testing of CNF and $\mathrm{CNF}$ /latex composite films, (a) CNF and $\mathrm{PMMA}_{176}$ latex, (b) $\mathrm{CNF}$ and $\mathrm{PMMA}_{1410}$ latex, (c) CNF and $\mathrm{PnBMA}_{176}$ latex (d) CNF and $\mathrm{PnBMA}_{1410}$ latex, (e) CNF reference film.

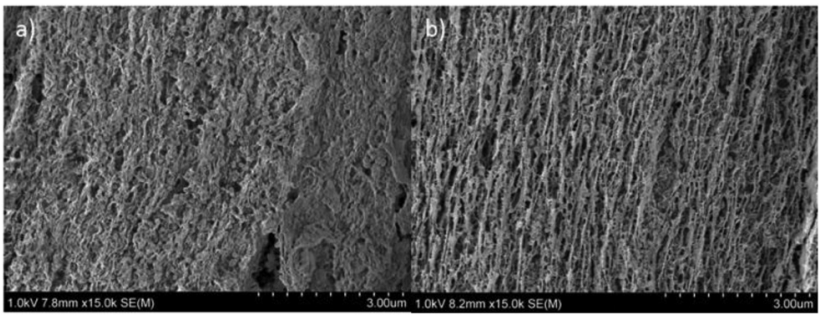

Fig. 11 The SEM pictures of fracture surfaces of CNF PMMA 1410 latex composite film, (a) before annealing and (b) after annealing.

appears that the fibrils have re-arranged after annealing to more resemble the CNF reference film or the $\mathrm{CNF} / \mathrm{P} n \mathrm{BMA}_{1410}$ latex composite film. Furthermore, rigid particles are no longer visible in the annealed film, similarly to the fracture surface of the $\mathrm{P} n \mathrm{BMA}_{1410}$ composite.

Hence, from these results it is suggested that the rigid PMMA particles will have more favorable interaction with CNF compared to the soft PnBMA particles at $50 \% \mathrm{RH}$ at room temperature, allowing reversible interaction between the positively charged corona and the negatively charged CNF. This

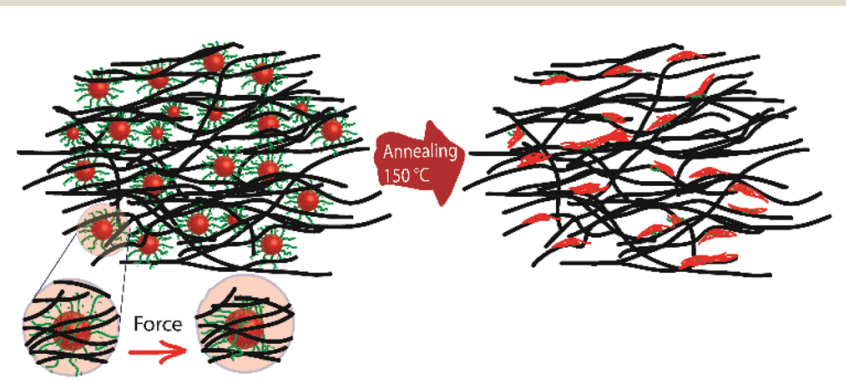

Fig. 12 Schematic illustration of the suggested strain-increasing mechanism using interacting $\mathrm{PMMA}_{1410}$ latex inside the CNF matrix. The left image shows the latex and CNF interaction prior to annealing with the increased strain mechanism, and the right image shows the same material after annealing, where the PMMA core smears out on the surface of CNF, causing a decreased interaction between the corona latex and CNF. 
bridging effect is schematically shown in Fig. 12. Clearly, rigid particles can be well distributed inside the CNF matrix at high loading, such as $25 \mathrm{wt} \%$ in this case, leading to a more flexible and strainable high-cellulose content material, without lowering the mechanical strength and stiffness to a large extent.

\section{Conclusions}

Two different types of latex particles have been synthesized using RAFT-mediated surfactant-free emulsion polymerization for which the nanoparticles were formed through a PISA-like mechanism. The particles consisted of amphiphilic block copolymers of either P(DMAEMA-co-MAA)- $b$-P $n$ BMA or P(DMAEMA-co-MAA)- $b$-PMMA, where the hydrophobic cores were chosen for their difference in $T_{\mathrm{g}}$, i.e. $25-35{ }^{\circ} \mathrm{C}$ (PnBMA) and $105-120{ }^{\circ} \mathrm{C}$ (PMMA). Their adsorption onto different types of cellulose-rich surfaces was investigated. With the aid of a QCM-D the latex particles were adsorbed to cellulose nanofibrils (CNF), exhibiting excellent adsorption, resulting in hydrophobic CNF films with contact angles above $87^{\circ}$ both before and after annealing for PnBMA latex. Adsorption of PMMA latexes resulted in high contact angles (between 59-100 $)$ which decreased upon annealing to $63-69^{\circ}$. The latexes were also adsorbed to cellulose filter paper and contact angles after adsorption were above $118^{\circ}$ for PnBMA-based latex without annealing, which can be compared to adsorption of PMMA-based latexes where no contact angle could be measured before thermal treatment, but after annealing the surfaces exhibited a contact angle of above $100^{\circ}$. These results show the possibility to manipulate the interface of a substrate by tailoring the core of latex, showing that the annealing step can be avoided by the utilization of a hydrophobic, low $T_{\mathrm{g}}$ particle core. The results also show that the model surfaces can be used to establish the adsorption mechanism for the latex onto cotton filters. One-pot composite films were produced by mixing CNF dispersion and latex nanoparticles. The incorporation of rigid large PMMA latexes increased the strain at break in comparison to the large, soft, PnBMA latexes. This increase was reduced if the composites were annealed, clearly showing that the rigidity of the particles had an effect on the strainability of the material, most likely through a bridging phenomenon between the particles and the CNF. This highly interesting finding should be considered when designing composites in the future, and its mechanism will be subjected to further investigations.

\section{Acknowledgements}

The authors would like to acknowledge the Knut and Alice Wallenberg foundation through the Wallenberg Wood Science Centre (WWSC) for financial support. F. H. acknowledges the Thunholm foundation. Pierre-Yves Dugas (C2P2) is greatly acknowledged for his help with cryo-TEM images.

\section{References}

1 M. Henriksson, L. A. Berglund, P. Isaksson, T. Lindström and T. Nishino, Biomacromolecules, 2008, 9, 1579-1585.

2 H. Fukuzumi, T. Saito, T. Iwata, Y. Kumamoto and A. Isogai, Biomacromolecules, 2008, 10, 162-165.

3 D. Klemm, B. Heublein, H. P. Fink and A. Bohn, AngewAngew. Chem., Int. Ed., 2005, 44, 3358-3393.

4 D. Klemm, F. Kramer, S. Moritz, T. Lindstrom, M. Ankerfors, D. Gray and A. Dorris, Angew. Chem., Int. Ed., 2011, 50, 5438-5466.

5 T. F. Fernandes, E. Trovatti, C. S. R. Freire, A. J. D. Silvestre, C. P. Neto, A. Gandini and P. Sadocco, Compos. Sci. Technol., 2011, 71, 1908-1913.

6 K. G. Satyanarayana, G. G. C. Arizaga and F. Wypych, Prog. Polym. Sci., 2009, 34, 982-1021.

7 A. Carlmark and E. E. Malmström, Biomacromolecules, 2003, 4, 1740-1745.

8 S. Hansson, E. Östmark, A. Carlmark and E. Malmström, ACS Appl. Mater. Interfaces, 2009, 1, 2651-2659.

9 A. Carlmark, E. Larsson and E. Malmström, Eur. Polym. J., 2012, 48, 1646-1659.

10 A. Boujemaoui, L. Carlsson, E. Malmström, M. Lahcini, L. Berglund, H. Sehaqui and A. Carlmark, ACS Appl. Mater. Interfaces, 2012, 4, 3191-3198.

11 F. L. Hatton, E. Malmström and A. Carlmark, Eur. Polym. J., 2015, 65, 325-339.

12 S. Utsel, E. E. Malmstrom, A. Carlmark and L. Wagberg, Soft Matter, 2010, 6, 342-352.

13 E. Larsson, C. C. Sanchez, C. Porsch, E. Karabulut, L. Wågberg and A. Carlmark, Eur. Polym. J., 2013, 49, 26892696.

14 M. N. Belgacem and A. Gandini, Compos. Interfaces, 2005, 12, 41-75.

15 A. Carlmark, Macromol. Chem. Phys., 2013, 214, 1539-1544.

16 C. Bruce, I. Javakhishvili, L. Fogelstrom, A. Carlmark, S. Hvilsted and E. Malmstrom, RSC Adv., 2014, 4, 2580925818.

17 S. Utsel, C. Bruce, T. Pettersson, L. Fogelström, A. Carlmark, E. Malmström and L. Wågberg, ACS Appl. Mater. Interfaces, 2012, 4, 6796-6807.

18 C. Aulin, I. Varga, P. M. Claesson, L. Wågberg and T. Lindström, Langmuir, 2008, 24, 2509-2518.

19 L. W. Daniel Solberg, Nord. Pulp Pap. Res. J., 2003, 18, 5.

20 Y.-Z. You, Q.-H. Zhou, D. S. Manickam, L. Wan, G.-Z. Mao and D. Oupický, Macromolecules, 2007, 40, 8617-8624.

21 J. Chiefari, Y. K. Chong, F. Ercole, J. Krstina, J. Jeffery, T. P. T. Le, R. T. A. Mayadunne, G. F. Meijs, C. L. Moad, G. Moad, E. Rizzardo and S. H. Thang, Macromolecules, 1998, 31, 5559-5562.

22 Q. Xiong, P. Ni, F. Zhang and Z. Yu, Polym. Bull., 2004, 53, 1-8.

23 M. Sahnoun, M.-T. Charreyre, L. Veron, T. Delair and F. D’Agosto, J. Polym. Sci., Part A: Polym. Chem., 2005, 43, 3551-3565.

24 W. Cai, W. Wan, C. Hong, C. Huang and C. Pan, Soft Matter, 2010, 6, 5554-5561. 
25 Y. Kitayama and M. Okubo, Polym. Chem., 2014, 5, 27842792.

26 A. Darabi, A. R. Shirin-Abadi, J. Pinaud, P. G. Jessop and M. F. Cunningham, Polym. Chem., 2014, 5, 6163-6170.

27 A. M. dos Santos, J. Pohn, M. Lansalot and F. D’Agosto, Macromol. Rapid Commun., 2007, 28, 1325-1332.

28 L. Carlsson, A. Fall, I. Chaduc, L. Wagberg, B. Charleux, E. Malmstrom, F. D'Agosto, M. Lansalot and A. Carlmark, Polym. Chem., 2014, 5, 6076-6086.

29 P. B. Zetterlund, S. C. Thickett, S. Perrier, E. Bourgeat-Lami and M. Lansalot, Chem. Rev., 2015, 115, 9745-9800.

30 B. Charleux, G. Delaittre, J. Rieger and F. D'Agosto, Macromolecules, 2012, 45, 6753-6765.

31 M. Lansalot, J. Rieger and F. D'Agosto, in Macromolecular Self-assembly, John Wiley \& Sons, Inc., 2016, DOI: 10.1002/ 9781118887813.ch2, pp. 33-82.

32 C. J. Ferguson, R. J. Hughes, B. T. T. Pham, B. S. Hawkett, R. G. Gilbert, A. K. Serelis and C. H. Such, Macromolecules, 2002, 35, 9243-9245.

33 C. J. Ferguson, R. J. Hughes, D. Nguyen, B. T. T. Pham, R. G. Gilbert, A. K. Serelis, C. H. Such and B. S. Hawkett, Macromolecules, 2005, 38, 2191-2204.

34 N. J. Warren and S. P. Armes, J. Am. Chem. Soc., 2014, 136, 10174-10185.

35 S. L. Canning, G. N. Smith and S. P. Armes, Macromolecules, 2016, 49, 1985-2001.

36 B. Alince, P. Arnoldova and R. Frolik, J. Appl. Polym. Sci., 2000, 76, 1677-1682.

37 B. Alince, M. Inoue and A. A. Robertson, J. Appl. Polym. Sci., 1976, 20, 2209-2219.

38 Y. Pan, M. Z. Wang and H. Xiao, Compos. Sci. Technol., 2013, 77, 81-86.

39 T. Boursier, I. Chaduc, J. Rieger, F. D’Agosto, M. Lansalot and B. Charleux, Polym. Chem., 2011, 2, 355-362.

40 G. Bouhadir, N. Legrand, B. Quiclet-Sire and S. Z. Zard, Tetrahedron Lett., 1999, 40, 277-280.

41 S. H. Thang, Y. K. Chong, R. T. A. Mayadunne, G. Moad and E. Rizzardo, Tetrahedron Lett., 1999, 40, 2435-2438.

42 T. Saito, Y. Nishiyama, J.-L. Putaux, M. Vignon and A. Isogai, Biomacromolecules, 2006, 7, 1687-1691.

43 T. Saito, M. Hirota, N. Tamura, S. Kimura, H. Fukuzumi, L. Heux and A. Isogai, Biomacromolecules, 2009, 10, 19921996.

44 S. Katz, R. P. Beatson and A. M. Scallan, Sven. Papperstidn., 1984, 87, 48-53.

45 N. T. Cervin, E. Johansson, J.-W. Benjamins and L. Wågberg, Biomacromolecules, 2015, 16, 822-831.
46 L. Wågberg, G. Decher, M. Norgren, T. Lindström, M. Ankerfors and K. Axnäs, Langmuir, 2008, 24, 784-795.

47 D. Horn, in Progress in Colloid \& Polymer Science, ed. G. Lagaly, F. H. Müller and A. Weiss, Steinkopff, 1978, ch. 28, vol. 65, pp. 251-264.

48 G. Sauerbrey, Z. Phys., 1959, 155, 206-222.

49 S. A. AB, Safety Data Sheet Butyl Methacrylate, http://www. sigmaaldrich.com/MSDS/MSDS/DisplayMSDSPage.do?country= SE\&language $=$ Sv\&productNumber $=$ M55909\&brand $=$ ALDRICH \&PageToGoToURL=http $\% 3 \mathrm{~A} \% 2 \mathrm{~F} \% 2 \mathrm{Fwww}$.sigmaaldrich. com\%2Fcatalog\%2Fproduct\%2Faldrich\%2Fm55909\%3Flang \%3Den, (accessed 06-21, 2016).

50 S. A. AB, Safety Data Sheet Methyl Methacrylate, http:/ www.sigmaaldrich.com/MSDS/MSDS/DisplayMSDSPage.do? country $=$ SE\&language $=$ sv\&productNumber $=$ M55909\&brand $=$ ALDRICH\&PageToGoToURL=http\%3A\%2F\%2Fwww.sigmaaldrich.com\%2Fcatalog\%2Fproduct $\% 2$ Faldrich $\% 2$ Fm $55909 \%$ 3Flang\%3Den, (accessed 06-21, 2016).

51 I. Chaduc, A. Crepet, O. Boyron, B. Charleux, F. D'Agosto and M. Lansalot, Macromolecules, 2013, 46, 60136023.

52 I. Chaduc, M. Girod, R. Antoine, B. Charleux, F. D’Agosto and M. Lansalot, Macromolecules, 2012, 45, 5881-5893.

53 S. J. Kweskin, K. Komvopoulos and G. A. Somorjai, Langmuir, 2005, 21, 3647-3652.

54 F. Özer, M. O. Beşkardeş and E. Pişkin, J. Appl. Polym. Sci., 2000, 78, 569-575.

55 F. Dinelli, C. Buenviaje and R. M. Overney, Thin Solid Films, 2001, 396, 138-145.

56 J. H. Lee and S. Chul Kim, Polym. J., 1984, 16, 453-459.

57 I. Szilagyi, G. Trefalt, A. Tiraferri, P. Maroni and M. Borkovec, Soft Matter, 2014, 10, 2479-2502.

58 Y. Ma, X. Cao, X. Feng, Y. Ma and H. Zou, Polymer, 2007, 48, 7455-7460.

59 M. Khayeta, M. Vázquez Álvarez, K. C. Khulbe, J. I. Mengual and T. Matsuura, Desalination, 2006, 200, 911.

60 M. Banerjee, S. Sain, A. Mukhopadhyay, S. Sengupta, T. Kar and D. Ray, J. Appl. Polym. Sci., 2014, 131, 39808.

61 Q. Liu, J. R. de Wijn and C. A. van Blitterswijk, J. Biomed. Mater. Res., 1998, 40, 257-263.

62 B. Li, H. Yuan and Y. Zhang, Compos. Sci. Technol., 2013, 89, 134-141.

63 G. Krala, A. Ubowska and K. Kowalczyk, Polym. Eng. Sci., 2014, 54, 1030-1037.

64 D. Tranchida, I. Lilge and H. Schönherr, Polym. Eng. Sci., 2011, 51, 1507-1512. 